\title{
Características reológicas e sensoriais de bebidas lácteas funcionais
}

\author{
Rheological and sensory characteristics of functional dairy \\ beverages
}

\author{
Raquel Guttierres Gomes ${ }^{1}$; Ana Lúcia Barretto Penna ${ }^{2 *}$
}

\begin{abstract}
Resumo
Neste trabalho foram estudados os efeitos das variáveis independentes: teor de soro de leite em pó $(3,0 ; 3,5 ; 4,0 \%)$, teor de leite em pó desnatado $(4,0 ; 5,0 ; 6,0 \%)$ e teor de isolado proteico de soja $(1,5 ; 2,0 ; 2,5 \%)$ nas características reológicas e sensoriais de bebidas lácteas funcionais. Em todos os testes adicionou-se $7 \%$ de sacarose aos ingredientes. Os parâmetros reológicos foram determinados em duplicata na temperatura de $10^{\circ} \mathrm{C}$ usando-se um reômetro de cone e placa, e ajustados pelo modelo da Lei da Potência. As amostras apresentaram comportamento de fluido não Newtoniano, nas curvas ascendentes e descendentes, típico de fluido tixotrópico. Os atributos sensoriais aceitabilidade geral; aparência e cor; consistência; sabor e aroma foram avaliados por uma equipe de 50 provadores não treinados, usando uma escala hedônica de 9 pontos, sendo os extremos 1 - desgostei muitíssimo e 9 gostei muitíssimo. A bebida láctea elaborada com $3 \%$ de soro de leite, $6 \%$ de leite em pó desnatado e 1,5\% de isolado proteico de soja (tratamento 3 ) foi a que obteve as maiores médias nos atributos e a preferida pelos provadores. As variáveis: leite em pó, isolado proteico de soja, e a interação entre soro de leite e leite em pó tiveram efeito positivo na consistência sensorial: quanto maior o teor destes ingredientes na formulação da bebida, mais os provadores gostaram da consistência das bebidas lácteas.

Palavras-chave: Alimentos funcionais, probióticos, consistência, isolado proteico de soja
\end{abstract}

\begin{abstract}
This research studied the effects of the independent variables whey protein concentrate - WPC $(3.0 ; 3.5$; $4.0 \%)$, skimmed milk powder - SMP $(4.0 ; 5.0 ; 6.0 \%)$, and isolated soy protein - IPS $(1.5 ; 2.0 ; 2.5 \%)$ on the rheological and sensorial characteristics of functional dairy beverages. In all tests $7 \%$ of sucrose was added to the ingredients. The rheological parameters were obtained in duplicate at the temperature of $10^{\circ} \mathrm{C}$ using a cone and plate rheometer, and fitted to the Power law model. The samples revealed a non-Newtonian fluid behavior both in the upward and downward curves, typical of a tixotropic fluid. The dairy beverages were submitted to a sensory analysis by a group of fifty untrained tasters who used a hedonic scale of nine points, the extremes being 1 - disliked extremely and 9 - liked extremely, in order to evaluate the following parameters: general acceptability; appearance and color; consistency; taste and aroma. The dairy beverage produced with 3\% WPC, 6\% SMP and 1.5\% IPS, (treatment 3), was the one that obtained the best average score for those attributes and was preferred by the tasters. The variables SMP and IPS and the interaction between WPC and SMP presented a positive effect on the sensory consistency attributes: the higher amount of those ingredients in the formula the more the tasters liked the consistency.
\end{abstract}

Key words: Functional foods, probiotics, consistency, isolated soy protein

${ }^{1}$ Engenheira de Alimentos, Doutoranda do Programa de Pós-graduação em Engenharia e Ciência de Alimentos, IBILCE - UNESP, São José do Rio Preto - SP.

2 Docente do Departamento de Engenharia e Tecnologia de Alimentos, IBILCE - UNESP, São José do Rio Preto - SP. E-mail: analucia@ibilce.unesp.br

* Autor para correspondência. 


\section{Introdução}

Os alimentos funcionais são vistos como promotores de saúde e podem estar relacionados à redução do risco de certas doenças, tais como câncer, hipertensão, diabetes, artrites e cardiopatias, incentivando o desenvolvimento de projetos para a caracterização de alimentos e/ou ingredientes que possuem propriedades terapêuticas, além das funções nutricionais normais. Estes alimentos poderiam melhorar as condições de saúde, promover o bem estar, prevenindo o surgimento precoce de doenças degenerativas, e conseqüentemente, reduzir a escalada dos custos nacionais da previdência social com o amparo à saúde (PUPIN, 2001; CICHOSKI et al., 2008; MORAES; COLLA, 2006).

A Resolução no19 de 30/04/1999, da Agência Nacional de Vigilância Sanitária fornece a definição legal de alimento funcional: "todo aquele alimento ou ingrediente que, além das funções nutricionais básicas, quando consumido como parte da dieta usual, produz efeitos metabólicos e/ou fisiológicos e/ou efeitos benéficos à saúde, devendo ser seguro para consumo sem supervisão médica" (BRASIL, 1999).

Atualmente, existem cinco segmentos de mercado onde encontrar alimentos funcionais: bebidas, produtos lácteos, produtos de confeitaria, produtos de panificação e cereais matinais. Os principais fatores que garantirão o desenvolvimento futuro serão: a qualidade do produto, segurança a respeito da procedência e qualidade do alimento, ética e conservação ambiental. O setor de alimentos funcionais registrou um crescimento de mais de $50 \%$ desde 2002 e atingiu, no ano de 2006, cerca de 647,1 milhões, de acordo com o instituto de pesquisa ACNielsen (SBAF - SOCIEDADE BRASILEIRA DE ALIMENTOS FUNCIONAIS, 2008). Entre as dificuldades para uma maior expansão incluem-se a legislação, confusão do consumidor com o conceito de alimento funcional, mensagens muito complicadas sobre os benefícios para a saúde e a percepção dos alimentos funcionais pelos consumidores (BRANDÃO, 2002).
A demanda dos consumidores por produtos saudáveis ou simplesmente seguros impulsionou a expansãodeprodutos comoiogurtes líquidos, bebidas à base de soja, bebidas isotônicas ou energéticas (SBAF, 2008). O setor contendo bebidas lácteas está entre as categorias com mais rápido crescimento. Entre 1999 e 2000, a taxa de crescimento de vendas foi de $10 \%$ para iogurtes líquidos e bebidas lácteas (excluindo leite). Entre 2000 e 2001, a taxa foi de $12 \%$, e $19 \%$, entre 2003 e 2004 . O lançamento de diversos novos produtos, sabores e embalagens inovadoras, e mais alternativas de bebidas lácteas e de soja, entrando, no mercado contribuíram para este crescimento. Os fatores primários de expansão global foram conveniência e praticidade, saúde e segurança, novos produtos e inovação da categoria (SBAF, 2008).

$\mathrm{Na}$ literatura estão disponíveis diversas pesquisas envolvendo o uso de soja em bebidas lácteas. A soja transformou-se em um insumo importante para o mercado de alimentos funcionais devido às propriedades ligadas a seus componentes: proteínas, lecitinas, fibras e fitoquímicos (ESTEVES; MONTEIRO, 2001). Nos Estados Unidos, principalmente, já é expressivo o emprego de proteína de soja em iogurtes e até em alguns tipos de bebidas lácteas. Essa tendência é muito promissora em nosso mercado, já que o Brasil é um grande produtor de soja, possibilitando uma ampla variedade de inovações na área de iogurtes (SANTOS, 2002). Com seu uso em composição com o soro de leite, é possível desenvolver bebidas nutritivas e com ótimo sabor e textura, além de uma excelente relação custo/benefícios (BUNGE ALIMENTOS, 2003).

Um exemplo disto foi o trabalho desenvolvido por Prudêncio et al. (2002), com o desenvolvimento de uma bebida a partir de extrato de soja adicionado de antioxidantes e soro de queijo ou água. As bebidas à base de extrato hidrossolúvel de soja apresentaram diferença quanto à preferência dos provadores quando o soro de queijo substituía a água e não 
entre as amostras adicionadas de antioxidantes (ácido ascórbico e ácido cítrico). A adição de ácido cítrico e ascórbico não influenciou o sabor das amostras. Drake et al. (2000) preparam iogurtes fortificados com $0 ; 1 ; 2,5$ e $5 \%$ de concentrado proteico de soja e acompanharam por um mês as propriedades químicas, sensoriais e microbiológicas. A contagem microbiológica, tempo de fermentação e o desenvolvimento da acidificação não foram afetados. A viscosidade (medida instrumental) e a textura (análise sensorial), aroma e sabor de soja tiveram um aumento durante o tempo de estocagem. O iogurte com 5\% de concentrado proteico de soja apresentou alterações na cor e perda da doçura quando comparado com os demais. $\mathrm{O}$ iogurte com 1 ou $2,5 \%$ de concentrado proteico de soja foram os que mais se assimilaram ao iogurte normal.

$\mathrm{Na}$ avaliação da qualidade de vários produtos lácteos, considerável importância é dada às propriedades de consistência e textura do produto, uma vez que estas influenciam em sua aceitabilidade pelos consumidores (AWADHWAL; SINGH, 1985). A manutenção da estabilidade do produto ou sua estrutura durante a estocagem é descrita pela reologia, principalmente para emulsões e outras dispersões. Na ciência dos alimentos, a reologia é usada para o estudo da estrutura dos alimentos como resposta à aplicação de força ou deformação. Várias são as razões para se conhecer as propriedades reológicas dos alimentos, dentre elas: efetuar o controle de qualidade de matériasprimas de processo ou fabricação de produtos finais, estudar a influência de componentes da formulação e relacionar a estrutura dos produtos com as suas características reológicas (STEFFE, 1996).

As propriedades reológicas de produtos lácteos têm sido pouco estudadas. Sob certas condições (isto é, moderada taxa de deformação, conteúdo de gordura inferior a $40 \%$ e a temperaturas superiores a $40^{\circ} \mathrm{C}$, nas quais a gordura está líquida e não ocorre aglutinação pelo frio) leite, leite desnatado e creme são fluidos com propriedades Newtonianas. Entretanto, leite cru e cremes exibem propriedades reológicas de fluidos não-Newtonianos quando são submetidos a condições em que é possível a solidificação dos glóbulos de gordura (abaixo de $40^{\circ} \mathrm{C}$ e baixas taxas de deformação) (FOX; MCSWEENEY, 1998). Leite condensado, creme e iogurte exibem comportamento tixotrópico (shear thinning), ou seja, sua viscosidade aparente é inversamente relacionada à taxa de deformação. Leites concentrados, manteiga, sorvete, iogurte e queijo são viscoelásticos (FOX; MCSWEENEY, 1998; VÉLEZ-RUIZ; BARBOSA-CANOVAS, 1998).

As propriedades reológicas de bebidas lácteas fermentadas de quatro diferentes marcas comerciais (Danone, Yoplait, Nestlé e Paulista) foram avaliadas por Penna e Oliveira (1998), usando-se um reômetro de cilindros concêntricos. Os parâmetros reológicos foram descritos pelos modelos de Ostwald - de Waele e de Herschel - Bulkley, nas temperaturas 5 e $25^{\circ} \mathrm{C}$. As amostras apresentaram comportamento de fluido não Newtoniano, do tipo pseudoplástico, com presença de tensão inicial de escoamento e tixotropia, como resultado da quebra estrutural. As curvas ascendentes das amostras das bebidas lácteas das marcas Danone, Yoplait e Paulista foram melhor descritas pelo modelo de Herschel-Bulkley, enquanto a da marca Nestlé obedeceu o modelo de Ostwald - de Waele.

A relação entre a qualidade e as propriedades reológicas de bebidas lácteas comerciais (Nestlé, Vigor, Batavo, Parmalat e Danone) foi conduzida por Penna, Sivieri e Oliveira (2001) com o objetivo de estabelecer parâmetros comparativos para o estudo de novas tecnologias de processo de bebidas lácteas. Amostras de cinco marcas comerciais de bebidas lácteas foram avaliadas quanto às suas características fisico-químicas, sensoriais e reológicas. Os parâmetros reológicos foram obtidos usando-se um reômetro de cone e placa e rotações de 10 a $250 \mathrm{rpm}$. Todas as amostras apresentaram comportamento não Newtoniano, com presença de tixotropia. Em geral, as curvas ascendentes apresentaram comportamento pseudoplástico, 
enquanto as curvas descendentes apresentaram comportamento dilatante ou Newtoniano. As amostras que apresentaram os maiores índices de consistência e maiores pseudoplasticidades foram as preferidas pelo painel sensorial.

$\mathrm{Na}$ literatura estão disponíveis diversos trabalhos sobre propriedades reológicas de bebidas lácteas, entretanto os efeitos da adição de proteínas de soja nos parâmetros reológicos ainda não foram estudados. Assim, equações específicas e relações entre qualidade sensorial e propriedades reológicas aplicáveis a produtos lácteos funcionais precisam ser estabelecidas. Neste trabalho o objetivo foi estudar as características reológicas e sensoriais de bebidas lácteas funcionais elaboradas com soro de leite, leite e isolado proteico de soja.

\section{Materiais e métodos}

\section{Preparação da bebida}

Foram estudados os efeitos das variáveis independentes: teor de soro de leite em pó $(3,0$; $3,5 ; 4,0 \%)$, teor de leite em pó desnatado $(4,0$; $5,0 ; 6,0 \%)$ e teor de isolado proteico de soja $(1,5$; 2,$0 ; 2,5 \%$, sobre as características reológicas e sensoriais de bebidas lácteas probióticas. Em todos os tratamentos foram acrescentados $7 \%$ de sacarose aos ingredientes. Em cada dia de processamento foram preparadas três formulações de bebidas lácteas, sendo o planejamento concluído num período de quatro semanas. Os ingredientes foram pesados e misturados na forma seca e reconstituídos emágua, conforme o planejamento dos experimentos (Tabela 1), em quantidades suficientes para preparar três litros de bebida láctea. A mistura foi aquecida a $85^{\circ} \mathrm{C}$, mantida em um banho termostatizado por 15 minutos, e resfriada em banho de água e gelo até atingir $43^{\circ} \mathrm{C}$, para receber $3 \%$ de cultura láctica (MY BIO 6, Ezal-Rhodia, contendo Streptococcus thermophilus, Lactobacillus delbrueckii subsp. bulgaricus, Lactobacillus acidophilus e Bifidobacterium) em condições assépticas. $\mathrm{O}$ produto foi incubado a $43^{\circ} \mathrm{C}$. O tempo de fermentação da bebida láctea foi calculado a partir do início da inoculação, até obter-se o valor de $\mathrm{pH}$ próximo a 4,5. Terminada a fermentação, foi feito um resfriamento inicial até aproximadamente $20^{\circ} \mathrm{C}$, e a quebra do coágulo por agitação manual durante 30 segundos, de forma padronizada. Em todos os experimentos foi acrescentado $1 \mathrm{~mL}$ de corante e 0,5 $\mathrm{mL}$ de aromatizante de pêssego (Duas Rodas Industrial, Jaraguá do Sul). Em seguida, foi feito o resfriamento final em banho de água e gelo. As bebidas lácteas foram embaladas em copos plásticos transparentes e armazenadas em refrigerador à temperatura de $5^{\circ} \mathrm{C}$, aproximadamente.

Tabela 1. Matriz de ensaios com as variáveis nas unidades codificadas e originais.

\begin{tabular}{lllllll}
\hline \multirow{2}{*}{ Tratamentos } & \multicolumn{3}{l}{ Níveis das variáveis codificadas } & \multicolumn{3}{l}{ Níveis das variáveis originais } \\
\cline { 2 - 7 } & $\mathrm{X}_{1}$ & $\mathrm{X}_{2}$ & $\mathrm{X}_{3}$ & Soro $(\%)$ & Leite $(\%)$ & Soja (\%) \\
\hline 1 & -1 & -1 & -1 & 3 & 4 & 1,5 \\
2 & +1 & -1 & -1 & 4 & 4 & 1,5 \\
3 & -1 & +1 & -1 & 3 & 6 & 1,5 \\
4 & +1 & +1 & -1 & 4 & 6 & 1,5 \\
5 & -1 & -1 & +1 & 3 & 4 & 2,5 \\
6 & +1 & -1 & +1 & 4 & 4 & 2,5 \\
7 & -1 & +1 & +1 & 3 & 6 & 2,5 \\
8 & +1 & +1 & +1 & 4 & 6 & 2,5 \\
9 & 0 & 0 & 0 & 3,5 & 5 & 2 \\
10 & 0 & 0 & 0 & 3,5 & 5 & 2 \\
11 & 0 & 0 & 0 & 3,5 & 5 & 2 \\
12 & 0 & 0 & 0 & 3,5 & 5 & 2 \\
\hline
\end{tabular}

$\mathrm{X}_{1}=$ soro de leite em pó; $\mathrm{X}_{2}=$ leite em pó desnatado; $\mathrm{X}_{3}=$ isolado proteico de soja. 
Planejamento estatístico dos ensaios experimentais

A Tabela 1 mostra as variáveis independentes e os níveis das variáveis que foram usados no planejamento experimental composto por 12 tratamentos. Os ensaios foram realizados com um planejamento experimental do tipo fatorial com dois níveis $\left(2^{3}\right)$ e quatro pontos centrais, utilizandose a metodologia de superfície de resposta (MONTGOMERY, 2001).

Foi feita a análise da variância (ANOVA) dos resultados das amostras e comparação entre as médias (teste de Tukey), utilizando-se o programa ESTAT, conforme Banzato e Kronka (1995).

Uma equação polinomial de segundo grau foi usada para estabelecer um modelo matemático preditivo da relação entre as variáveis independentes e a resposta (BOX, HUNTER; HUNTER, 1978), cuja equação geral é:

$\mathrm{y}=\mathrm{b}_{\mathrm{o}}+\mathrm{b}_{1} \mathrm{x}_{1}+\mathrm{b}_{2} \mathrm{x}_{2}+\mathrm{b}_{3} \mathrm{x}_{3}+\mathrm{b}_{11} \mathrm{x}_{1}^{2}+\mathrm{b}_{22} \mathrm{x}_{2}^{2}+\mathrm{b}_{33} \mathrm{x}_{3}^{2+}$ $\mathrm{b}_{12} \mathrm{x}_{1} \mathrm{x}_{2}+\mathrm{b}_{13} \mathrm{x}_{1} \mathrm{x}_{3}+\mathrm{b}_{23} \mathrm{x}_{2} \mathrm{x}_{3}+\varepsilon$ (Equação 1)

em que:

$\mathrm{y}$ - é a função resposta genérica

$\mathrm{x}$ - são as variáveis codificadas, obtidas a partir das variáveis originais

b - são os coeficientes estimados pela técnica de mínimos quadrados.

$\varepsilon$ - é o resíduo, medindo o erro experimental.

A influência das variáveis foi visualizada pela representação tridimensional da superfície de resposta e das linhas de iso-resposta, empregandose o programa computacional STATISTICA versão 5.0 (Tulsa, USA). Em todas as análises considerouse um nível de significância de 5\%.

\section{Análise sensorial das bebidas lácteas}

As bebidas lácteas foram submetidas à análise sensorial por uma equipe de 50 provadores não treinados, recrutados entre visitantes, alunos e funcionários do Instituto de Biociências, Letras e Ciências Exatas - UNESP. Os parâmetros avaliados foram: aceitabilidade geral - traduzida pelo conjunto, relativa à primeira impressão causada pelo produto como um todo, sem representar a média das notas das outras características avaliadas; aparência e cor - diz respeito ao aspecto visual do produto; consistência - relacionada ao corpo do produto quando consumido; sabor - sensação integrada dos sentidos do olfato e do gosto; aroma - relacionado às substâncias liberadas durante o consumo das bebidas lácteas. Para expressar sua opinião a respeito das amostras, os provadores utilizaram uma escala hedônica de 9 pontos, sendo os extremos 1 - desgostei muitíssimo e 9 - gostei muitíssimo, conforme descrito por Moraes (1983). As amostras foram servidas refrigeradas $\left(8\right.$ a $\left.10^{\circ} \mathrm{C}\right)$, em potes brancos de plástico com capacidade de 70 $\mathrm{mL}$, codificados com números aleatórios, em cabines individuais, em laboratório de análise sensorial, sempre duas horas antes ou depois das refeições, no período mais adequado para a realização destas avaliações.

\section{Caracterização reológica das bebidas lácteas}

Os parâmetros foram obtidos em duplicata na temperatura de $10^{\circ} \mathrm{C}$ usando-se um reômetro de cone e placa, modelo RVDV III (Brookfield, Stoughton, USA), com camisa termostatizada. O aumento da tensão de cisalhamento foi obtido pelo aumento da rotação, a partir da variação contínua da velocidade angular do cone. Foram utilizadas rotações entre 5 e $61 \mathrm{rpm}$ com acréscimo de $2 \mathrm{rpm}$ a cada 10 segundos, em curvas ascendentes e descendentes e cone CP41. A taxa de deformação variou de 10 a $122 \mathrm{~s}^{-1}$. Os parâmetros reológicos foram determinados usandose o programa computacional Reocalc for Windows (Brookfield, Stoughton, USA). 


\section{Resultados e discussões}

\section{Avaliação sensorial das bebidas lácteas}

A bebida láctea elaborada conforme os tratamentos 2 e 3 foram as que obtiveram as maiores médias nos atributos aparência e cor, consistência e aroma (Tabela 2) no entanto, sem apresentar diferença signficativa. A preferência das amostras pelos provadores pode estar relacionada à composição das bebidas lácteas, que continham 3\% de soro de leite, $6 \%$ de leite em pó e $1,5 \%$ de isolado proteico de soja (tratamento 3 ) e $4 \%$ de soro de leite, $4 \%$ de leite em pó e $1,5 \%$ de isolado proteico de soja (tratamento 2). A bebida láctea elaborada conforme o tratamento 2 obteve o maior valor para o atributo sabor, com diferença significativa das bebidas elaboradas conforme os tratamentos $4,5,7,8$.

Tabela 2. Valores médios dos atributos sensoriais das bebidas lácteas funcionais.

\begin{tabular}{llllll}
\hline Tratamentos & Aceitabilidade Geral & Aparência e Cor & Consistência & Sabor & Aroma \\
\hline 1 & $6,2^{\mathrm{AB}}$ & $7,2^{\mathrm{A}}$ & $5,8^{\mathrm{A}}$ & $5,6^{\mathrm{ABC}}$ & $6,6^{\mathrm{A}}$ \\
2 & $6,6^{\mathrm{AB}}$ & $7,4^{\mathrm{A}}$ & $6,2^{\mathrm{A}}$ & $6,4^{\mathrm{A}}$ & $6,7^{\mathrm{A}}$ \\
3 & $6,8^{\mathrm{AB}}$ & $7,5^{\mathrm{A}}$ & $6,4^{\mathrm{A}}$ & $5,4^{\mathrm{ABC}}$ & $6,7^{\mathrm{A}}$ \\
4 & $6,2^{\mathrm{AB}}$ & $6,9^{\mathrm{A}}$ & $6,3^{\mathrm{A}}$ & $5,1^{\mathrm{BC}}$ & $5,8^{\mathrm{A}}$ \\
5 & $5,9^{\mathrm{AB}}$ & $6,9^{\mathrm{A}}$ & $5,4^{\mathrm{A}}$ & $5,0^{\mathrm{BC}}$ & $6,3^{\mathrm{A}}$ \\
6 & $6,0^{\mathrm{AB}}$ & $7,2^{\mathrm{A}}$ & $5,8^{\mathrm{A}}$ & $5,2^{\mathrm{ABC}}$ & $6,4^{\mathrm{A}}$ \\
7 & $6,7^{\mathrm{AB}}$ & $7,4^{\mathrm{A}}$ & $6,3^{\mathrm{A}}$ & $5,1^{\mathrm{BC}}$ & $6,3^{\mathrm{A}}$ \\
8 & $5,7^{\mathrm{B}}$ & $6,6^{\mathrm{A}}$ & $5,6^{\mathrm{A}}$ & $4,4^{\mathrm{C}}$ & $5,5^{\mathrm{A}}$ \\
9 & $6,6^{\mathrm{AB}}$ & $7,4^{\mathrm{A}}$ & $6,1^{\mathrm{A}}$ & $5,6^{\mathrm{ABC}}$ & $6,6^{\mathrm{A}}$ \\
10 & $6,2^{\mathrm{AB}}$ & $7,4^{\mathrm{A}}$ & $6,1^{\mathrm{A}}$ & $5,5^{\mathrm{ABC}}$ & $6,7^{\mathrm{A}}$ \\
11 & $6,8^{\mathrm{A}}$ & $7,4^{\mathrm{A}}$ & $6,2^{\mathrm{A}}$ & $5,5^{\mathrm{ABC}}$ & $6,7^{\mathrm{A}}$ \\
12 & $6,4^{\mathrm{AB}}$ & $6,9^{\mathrm{A}}$ & $6,3^{\mathrm{A}}$ & $5,9^{\mathrm{AB}}$ & $6,5^{\mathrm{A}}$ \\
\hline
\end{tabular}

A, B, C Letras iguais para a mesma coluna indicam que não há diferença significativa $(\mathrm{p}<0,05)$. Média de 50 provadores.

A aceitabilidade geral é entendida pelo conjunto relativo à primeira impressão causada pelo produto como um todo. Os valores obtidos para este atributo variaram de 5,7 a 6,8 , com diferença significativa entre os tratamentos. A maior nota foi obtida pela bebida láctea do tratamento $11(3,5 \%$ de soro de leite, $5 \%$ de leite em pó desnatado e $2 \%$ de isolado proteico de soja), seguida pela bebida láctea do tratamento 3 (3\% de soro de leite, $6 \%$ de leite em pó desnatado e $1,5 \%$ de isolado proteico de soja), que por sua vez não diferiu estatisticamente dos demais (Tabela 2). O produto que obteve a menor preferência foi o elaborado com $4 \%$ de soro de leite, $6 \%$ de leite em pó desnatado e $2,5 \%$ de isolado proteico de soja (tratamento 8).

A aparência e a cor estão baseadas no aspecto visual do produto, como a presença ou não de soro na superfície, produção de gás, cor característica, ausência de grumos e homogeneidade do produto (MADUREIRA, 2004). Os resultados obtidos na análise de aparência e cor variaram de 6,6 a 7,5, porém sem diferença significativa entre os tratamentos (Tabela 2). Todas as bebidas apresentaram aspecto homogêneo, sem a presença de grumos, gás e cor característica (corante de urucum) para aroma de pêssego.

As notas do atributo consistência variaram de 5,4 (indiferente) a 6,4 (gostei ligeiramente), entretanto não houve diferença significativa entre os tratamentos, indicando que os provadores gostaram igualmente da consistência das amostras, apesar da diferença no teor de sólidos totais. As bebidas apresentaram-se cremosas, encorpadas e sem grumos, porém com sinérese e separação de fases. Na avaliação da consistência deve-se levar em conta o corpo do produto quando consumido. 
Coágulo com grumos, corpo fraco e problemas com a viscosidade são defeitos que podem levar à rejeição por parte dos consumidores (GUEDES NETO; FONSECA; SOUZA, 2003). A granulação pode ser causada pelo baixo desenvolvimento de acidez (PINHEIRO, 2003) e por problemas com a dissolução dos sólidos que farão parte da composição das bebidas lácteas. A baixa viscosidade pode ser causada pela menor concentração de sólidos totais, tratamento térmico e homogeneização insuficientes, agitação incorreta, destruição do gel durante a acidificação, tipo de cultura láctica e temperatura de incubação muito baixa (GUEDES NETO; FONSECA; SOUZA, 2003). A textura adequada dos produtos com baixo teor de gordura pode ser obtida pela escolha de uma cultura láctica composta por bactérias que produzam substâncias que melhorem a viscosidade e a cremosidade do produto final, e também a utilização de sólidos de origem láctea, como os concentrados proteicos e/ou misturas de hidrocolóides (FIORAVANTE, 2001).

Os resultados obtidos nas avaliações do atributo sabor variaram de 4,4 a 6,4 pontos, sendo a maior nota obtida para a bebida elaborada conforme $\mathrm{o}$ tratamento 2. Dois dos tratamentos (5 e 8) elaborados com a maior porcentagem de isolado proteico de soja foram os que receberam as menores notas para sabor. Provavelmente os demais constituintes dessas formulações não foram suficientes para mascarar o sabor de soja, normalmente relacionado à rejeição pelo consumidor.

Tortelli (2002), em um estudo utilizando a formulação base para a bebida láctea de $55 \%$ de extrato hidrossolúvel de soja, $35 \%$ de leite de vaca e $10 \%$ de soro de leite, fermentada com cultura mista de S. thermophilus e L. delbrueckii subsp. bulgaricus, mostrou que durante o armazenamento a qualidade físico-química e sensorial apresentou alterações significativas. A acidez ficou bem evidenciada a partir do $7^{\circ}$ dia e, no $10^{\circ}$ dia de armazenamento, a aparência e homogeneidade permaneceram praticamente inalteradas, havendo também pouca alteração no aroma global e ácido, porém o sabor apresentou alterações significativas no sabor de soja.

Para o atributo aroma, as variações foram de 5,5 a 6,7 , sem diferença significativa entre os tratamentos (Tabela 2). Apesar dos resultados satisfatórios com o aroma utilizado, diferentes aromas podem apresentar maior capacidade de mascarar o sabor típico da soja, apresentar maior aceitabilidade pelos provadores, ou ainda, outros aromas podem apresentar uma melhor combinação com produtos de soja do que o produto testado. Assim, estudos complementares podem ser realizados para uma melhor decisão sobre qual é a combinação de aromas adequados para uso em bebidas lácteas contendo proteínas de soja, que atendam ao paladar do brasileiro. O sabor e aroma dos produtos fermentados devem ser ligeiramente ácidos, portanto dependem dos microrganismos da cultura e de seu metabolismo durante a fermentação (GUEDES NETO; FONSECA; SOUZA, 2003).

De um modo geral, as notas individuais dos atributos sensoriais das bebidas lácteas apresentaram uma variação muito grande, ou seja, alguns gostaram muito e outros desgostaram muito, com médias variando na faixa de 4,4 a 7,5 .

A partir dos resultados médios dos tratamentos de cada atributo avaliado na análise sensorial procedeu-se a regressão múltipla para a obtenção de uma equação polinomial completa. Para a aparência e cor, consistência e aroma, não houve diferença significativa entre os tratamentos, isto significa que as variáveis estudadas não tiveram influência sobre estes atributos sensoriais. Para a aceitabilidade geral e sabor, a análise de variância mostrou não ser significativa estatisticamente as regressões obtidas (aceitabilidade geral $\mathrm{R}^{2}=0,2938, \mathrm{p}=0,3280$ e sabor $\mathrm{R}^{2}=0,5433, \mathrm{p}=0,1626$ ). Por isso, as equações não estão sendo apresentadas. Desta forma, não foi possível relacionar a preferência do painel dos provadores com as variações nos teores de soro de leite, leite em pó e isolado proteico de soja, uma vez que houve grande variação nas notas emitidas pelos 
provadores. Além disso, outros fatores, além dos ingredientes da formulação podem ter influenciado na aceitabilidade sensorial dos produtos.

\section{Caracterização reológica das bebidas lácteas}

A partir dos dados de taxa de deformação e tensão de cisalhamento, os parâmetros reológicos das bebidas lácteas foram ajustados pelo modelo da Lei da Potência (Tabela 3). Os reogramas das bebidas lácteas estão apresentados nas Figuras 1 (curvas ascendentes) e 2 (curvas descendentes). As amostras apresentaram comportamento de fluido não Newtoniano, nas curvas ascendentes e descendentes. A diferença entre as curvas ascendentes e descendentes da relação cisalhamento/deformação, com a formação de uma curva de histerese é a medida da extensão da quebra estrutural causada pelo cisalhamento. Este comportamento é típico de fluido tixotrópico; quanto maior a área sob a curva, maior o efeito tixotrópico (HOLDSWORTH, 1993).

A maior histerese foi observada na bebida láctea preparada conforme o tratamento 7 , em cuja formulação contém $3 \%$ de soro de leite, $6 \%$ de leite em pó desnatado e $2,5 \%$ de isolado proteico de soja, produto que apresentou o maior índice de consistência. Este comportamento também foi observado por Penna (2000), que relatou maior tixotropia em bebidas lácteas que apresentaram os maiores índices de consistência, cujos teores de sólidos totais variaram de 9,50 a 9,91\%. Desta forma, quanto maior o teor de sólidos totais da amostra, maior a degradação causada pelo cisalhamento contínuo. O tixotropismo pode ser atribuído à presença de ligações de hidrogênio presentes entre as micelas coloidais e que rompidas pela agitação voltam a se formar no sistema em repouso (BOBBIO; BOBBIO, 1992).

Os índices de consistência $(\mathrm{K})$ foram maiores para as curvas ascendentes em comparação com as descendentes (Tabela 3). Na curva descendente, o índice de comportamento (n) foi maior, demonstrando que o produto após cisalhado apresenta comportamento mais próximo aos dos fluidos Newtonianos $(\mathrm{n}=1)$. Em algumas bebidas, o comportamento observado foi dilatante $(n>1)$. Nos fluidos dilatantes ocorre o aumento da viscosidade aparente com o aumento da velocidade de cisalhamento. O fenômeno de dilatância é explicado pela existência no líquido de um sistema de partículas densamente empacotado e, quando submetido a uma tensão de cisalhamento, as partículas se separam. Os vazios entre elas aumentam e são imediatamente preenchidos com líquido da fase contínua. Como o líquido é insuficiente para saturar o sistema, preencher os vazios e cobrir as partículas, a viscosidade aparente aumenta rapidamente e o sistema parece secar ou solidificar (CARVALHO, 1990).

As bebidas lácteas apresentaram índice de consistência (K) variando de 0,012 (tratamento 2) a 1,040 Pa.s (tratamento 7) para as curvas ascendentes e 0,004 Pa.s ${ }^{\mathrm{n}}$ (tratamento 4) a 0,128 Pa.s ${ }^{\mathrm{n}}$ (tratamento 3) para as curvas descendentes e índice de comportamento do escoamento (n) variando de 0,605 (tratamento 3) a 1,310 (tratamento 2) para as curvas ascendentes e 0,884 (tratamento 7) a 1,458 (tratamento 2) para as curvas descendentes. Os coeficientes de determinação $\left(\mathrm{R}^{2}\right)$ variaram de 0,986 a 0,996 para as curvas ascendentes e de 0,956 a 0,986 para as curvas descendentes, explicando mais que $95 \%$ dos resultados experimentais, justificando o uso deste modelo para fins preditivos. 
Tabela 3. Parâmetros reológicos das bebidas lácteas, obtidos pelo modelo da Lei da Potência $\left(\tau=\mathrm{K} \dot{\gamma}^{\mathrm{n}}\right)$.

\begin{tabular}{|c|c|c|c|c|c|c|}
\hline \multirow[b]{2}{*}{ Tratamentos } & \multicolumn{3}{|c|}{ Curvas ascendentes } & \multicolumn{3}{|c|}{ Curvas descendentes } \\
\hline & $\begin{array}{l}\mathrm{K} \\
\mathrm{Pa} . \mathrm{s}^{\mathrm{n}}\end{array}$ & $\mathrm{n}$ & $\mathrm{R}^{2}$ & $\begin{array}{l}\mathrm{K} \\
\text { Pa.s }{ }^{\mathrm{n}}\end{array}$ & $\mathrm{n}$ & $\mathrm{R}^{2}$ \\
\hline 1 & $0,086^{\mathrm{D}}$ & $0,918^{\mathrm{BC}}$ & 0,986 & $0,025^{\mathrm{FG}}$ & $1,152^{\mathrm{BC}}$ & 0,975 \\
\hline 2 & $0,012^{\mathrm{D}}$ & $1,310^{\mathrm{A}}$ & 0,996 & $0,043^{\mathrm{DE}}$ & $1,458^{\mathrm{A}}$ & 0,986 \\
\hline 3 & $0,797^{\mathrm{AB}}$ & $0,605^{\mathrm{E}}$ & 0,987 & $0,027^{\mathrm{F}}$ & $1,039^{\mathrm{CD}}$ & 0,956 \\
\hline 4 & $0,463^{\mathrm{BC}}$ & $0,771^{\mathrm{D}}$ & 0,991 & $0,004^{\mathrm{H}}$ & $1,044^{\mathrm{CD}}$ & 0,961 \\
\hline 5 & $0,091^{\mathrm{D}}$ & $0,912^{\mathrm{BC}}$ & 0,994 & $0,013^{\mathrm{GH}}$ & $1,054^{\mathrm{CD}}$ & 0,965 \\
\hline 6 & $0,082^{\mathrm{D}}$ & $1,026^{\mathrm{B}}$ & 0,992 & $0,071^{\mathrm{C}}$ & $1,345^{\mathrm{AB}}$ & 0,974 \\
\hline 7 & $1,040^{\mathrm{A}}$ & $0,620^{\mathrm{E}}$ & 0,985 & $0,105^{\mathrm{B}}$ & $0,884^{\mathrm{D}}$ & 0,956 \\
\hline 8 & $0,130^{\mathrm{CD}}$ & $0,983^{\mathrm{B}}$ & 0,993 & $0,128^{\mathrm{A}}$ & $1,292^{\mathrm{AB}}$ & 0,966 \\
\hline 9 & $0,087^{\mathrm{D}}$ & $0,969^{\mathrm{B}}$ & 0,994 & $0,044^{\mathrm{D}}$ & $1,162^{\mathrm{BC}}$ & 0,966 \\
\hline 10 & $0,176^{\mathrm{CD}}$ & $0,847^{\mathrm{CD}}$ & 0,986 & $0,101^{\mathrm{B}}$ & $1,002^{\mathrm{CD}}$ & 0,963 \\
\hline 11 & $0,274^{\mathrm{CD}}$ & $0,854^{\mathrm{CD}}$ & 0,990 & $0,029^{\mathrm{F}}$ & $1,174^{\mathrm{BC}}$ & 0,966 \\
\hline 12 & $0,070^{\mathrm{D}}$ & $1,030^{\mathrm{B}}$ & 0,993 & $0,030^{\mathrm{EF}}$ & $1,197^{\mathrm{BC}}$ & 0,970 \\
\hline
\end{tabular}

A, B, C, D, E, F, G Letras iguais para a mesma coluna indicam que não há diferença significativa ( $<<0,05)$. $\mathrm{K}-$ índice de consistência, $\mathrm{n}-$ índice de comportamento do escoamento e $\mathrm{R}^{2}$ - coeficiente de determinação.

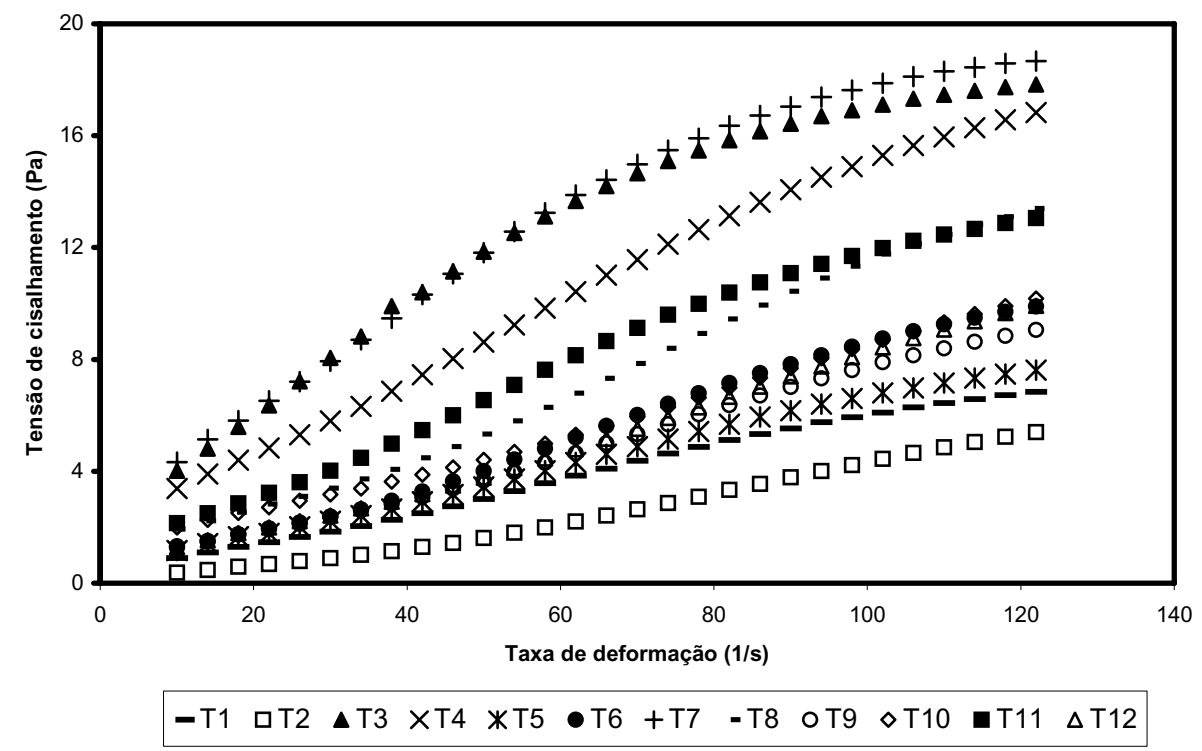

Figura 1. Reogramas das bebidas lácteas funcionais obtidos a partir da relação entre taxa de deformação e tensão de cisalhamento, curvas ascendentes. 


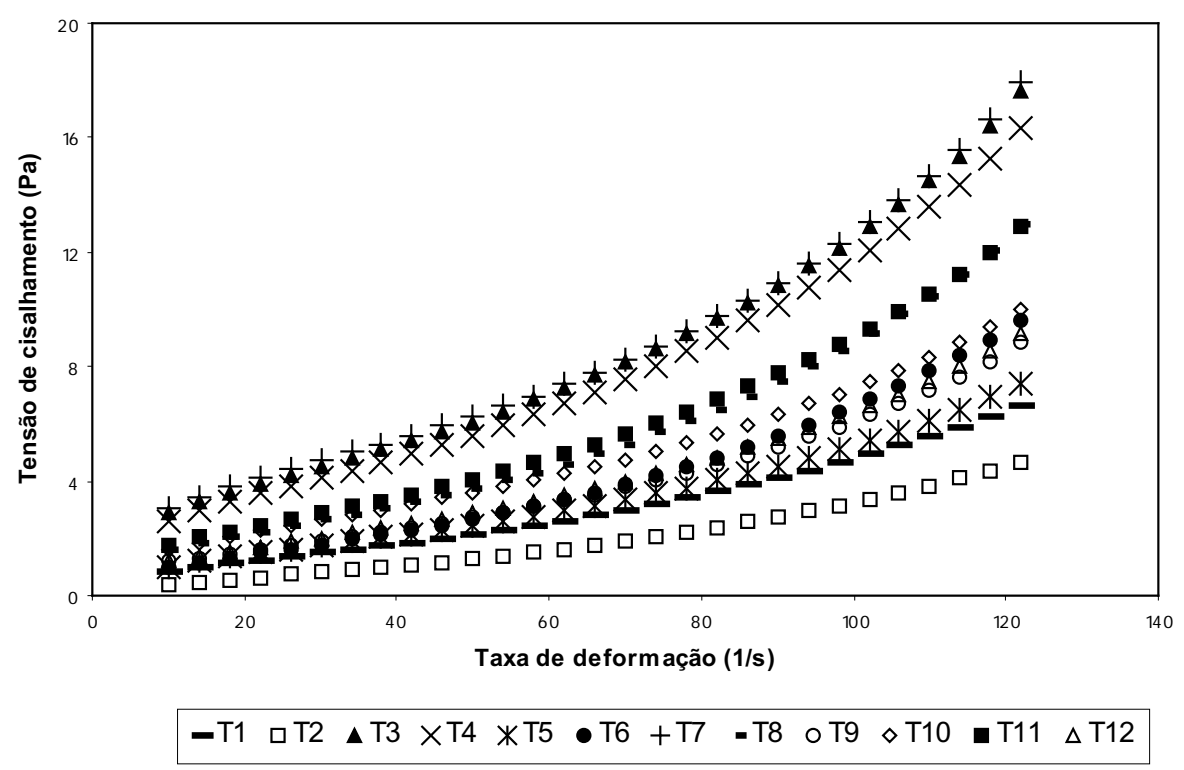

Figura 2. Reogramas das bebidas lácteas funcionais obtidos a partir da relação entre taxa de deformação e tensão de cisalhamento, curvas descendentes.

Para as curvas ascendentes, a análise de variância dos resultados do índice de consistência $(\mathrm{K})$ e do índice de comportamento do escoamento (n) demonstrou que houve diferença significativa entre os tratamentos, conforme mostram os resultados do teste de Tukey (Tabela 3).

A partir dos valores médios dos parâmetros índice de consistência e índice de comportamento de escoamento procedeu-se a regressão múltipla para a obtenção de uma equação polinomial completa, para relacionar as variáveis de soro de leite, leite em pó e isolado proteico de soja com os parâmetros reológicos obtidos. Eliminaram-se os coeficientes não significativos $(\mathrm{p}>0,05)$, obtendo-se um modelo ajustado como mostram as Equações 1 (índice de consistência) e 2 (índice de comportamento do escoamento).

$\mathrm{Y}_{1}=0,238-0,150 \cdot \mathrm{X}_{1}+0,229 \cdot \mathrm{X}_{2}-0,125 \cdot \mathrm{X}_{1} \cdot \mathrm{X}_{2}$ (Equação 1)

$\mathrm{Y}_{2}=0,920+0,129 \cdot \mathrm{X}_{1}-0,140 \cdot \mathrm{X}_{2}($ Equação 2$)$
A análise de variância dos modelos polinomiais índice de consistência $(\mathrm{K})$ e índice de comportamento do escoamento (n) mostrou que o coeficiente de determinação para os modelos foram de $90,76 \%$ e $92,37 \%$ e o nível de significância de 0,057 e 0,040 , respectivamente. $\mathrm{O}$ índice de consistência $(\mathrm{K})$ é dependente da variável $\mathrm{X}_{1}$ (soro de leite), $\mathrm{X}_{2}$ (leite em pó) e da interação $X_{1} \cdot X_{2}$ (soro de leite e leite em pó), e o índice de comportamento do escoamento (n) é dependente das variáveis $\mathrm{X}_{1}$ (soro de leite) e $\mathrm{X}_{2}$ (leite em pó).

As Figuras 3 e 4 mostram as superfícies de resposta da relação entre as variáveis (leite em pó e soro de leite) e os parâmetros reológicos (índice de consistência e índice de comportamento do escoamento). Quanto maior o teor de leite em pó e soro de leite, maior o índice de consistência das bebidas lácteas, enquanto o índice de comportamento do escoamento teve resultado oposto.

De forma geral, a viscosidade aumenta com o incremento da concentração de sólidos solúveis. Esta maior viscosidade está associada à redução do fluido para lubrificação inter-molecular e formação 
de hidratos pelos íons e moléculas, e agregados moleculares que aumentam o atrito entre as camadas de fluido (VITALI, 1983).

A bebida láctea que apresentou maior índice de consistência $\left(K=1,040\right.$ Pa.s $\left.{ }^{n}\right)$ foi a elaborada conforme o tratamento 7 (3\% de soro de leite, $6 \%$ de leite em pó desnatado e $2,5 \%$ de isolado proteico de soja e demais ingredientes da formulação totalizando $17,40 \%$ de sólidos totais). O produto elaborado conforme o tratamento 8 continha o maior teor de sólidos totais (19,5\%), seguido pelos tratamentos $4 \mathrm{e}$ 7, com $18,45 \%$ e $17,43 \%$, respectivamente. A bebida láctea elaborada conforme o tratamento $3(3 \%$ de soro de leite, $6 \%$ de leite em pó desnatado e $1,5 \%$ de isolado proteico de soja) apresentou o menor índice de comportamento do escoamento $(n=0,605)$, ou seja, característica de fluido pseudoplástico.

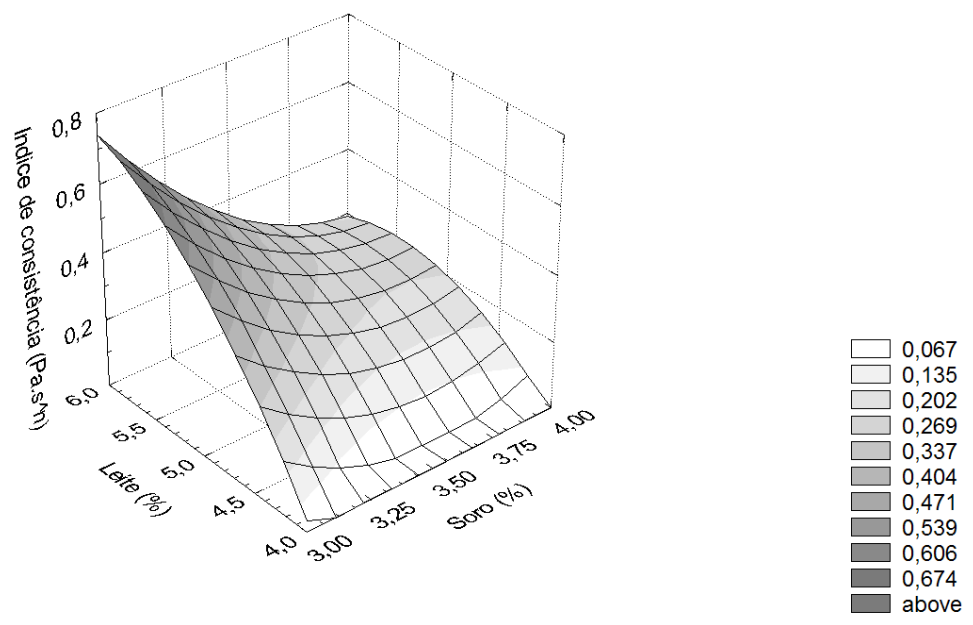

Figura 3. Efeito dos teores de soro de leite e leite em pó sobre o índice de consistência (K) das bebidas lácteas, curva ascendente.

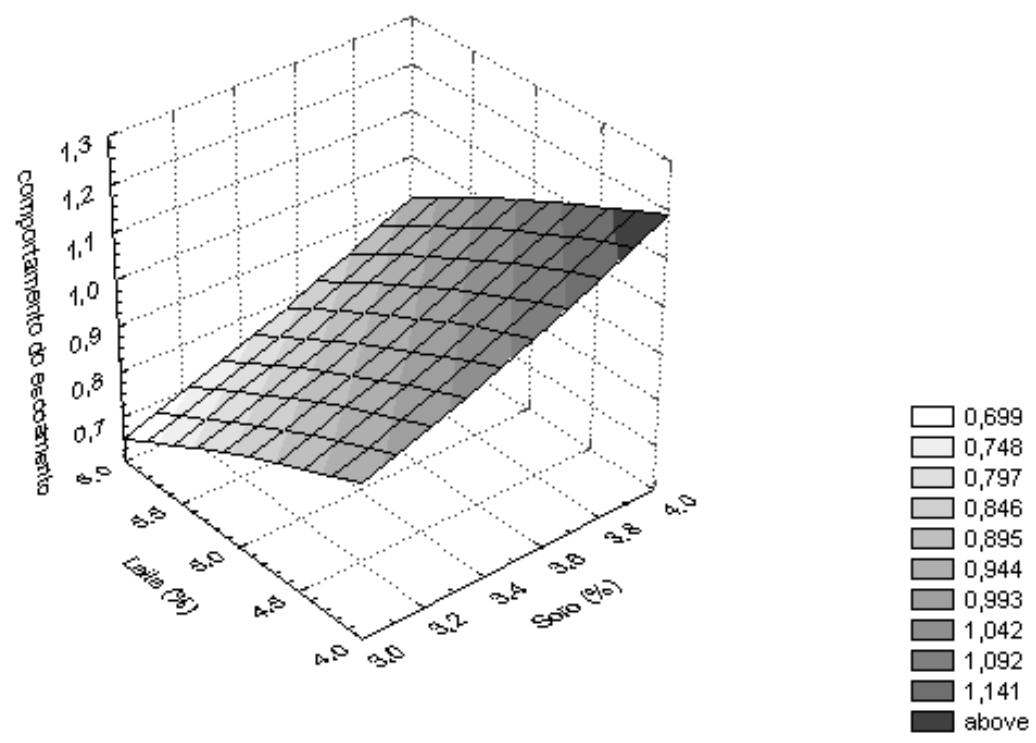

Figura 4. Efeito dos teores de soro de leite e leite em pó sobre índice de comportamento do escoamento (n) das bebidas lácteas, curvas ascendente. 
O comportamento reológico das bebidas lácteas com proteínas de soja foi semelhante ao observado em bebidas lácteas comerciais em estudo realizado por Penna, Sivieri e Oliveira (2001), em que relacionaram a pseudoplasticidade do produto à preferência. Todas as amostras demonstraram comportamento não Newtoniano com tixotropia, sendo que as curvas ascendentes apresentaram comportamento pseudoplástico, enquanto as curvas descendentes, comportamento dilatante em quase todas as marcas. O modelo da Lei da Potência foi o mais adequado para descrever o comportamento reológico.

$\mathrm{Na}$ literatura estão descritos diversos fatores que afetam as propriedades reológicas dos produtos fermentados. Renkema (2004) estudoua relaçãoentre as propriedades reológicas e a estrutura da cadeia em isolados proteicos de soja em função do valor de $\mathrm{pH}$ $(3,8,5,2$ e 7,6) e da força iônica (concentração de cloreto de sódio de 0,0, 0,2 e 0,5 M). O experimento mostrou que as propriedades reológicas variaram com o $\mathrm{pH}$ e a força iônica devido às diferenças na estrutura das cadeias pela quantidade de proteínas incorporadas. Haque, Richardson e Morris (2001) afirmam que as características reológicas também são afetadas pelas condições de fermentação. Aumentando a temperatura (de 37 a $46^{\circ} \mathrm{C}$ ) ocorre um aumento na taxa de redução do $\mathrm{pH}$ na formação da estrutura, na firmeza do gel e na viscosidade do iogurte. O aumento na taxa de fermentação é atribuído ao aumento da atividade metabólica das bactérias lácteas. A formação do gel é atribuída ao aumento na extensão e na força das ligações hidrofílicas quando a temperatura de fermentação é alcançada (HAQUE; RICHARDSON; MORRIS, 2001).

Os fatores que afetam as propriedades de fluxo podem ser: degradação enzimática, efeitos físicoquímicos $(\mathrm{pH})$ e efeitos físicos (teor de sólidos) (CAMPOS, 1989).

Para a curva descendente, a análise de variância dos resultados do índice de consistência $(\mathrm{K})$ e do índice de comportamento do escoamento (n) demonstrou que houve diferença significativa entre os tratamentos (Tabela 3). A partir dos valores médios dos parâmetros índice de consistência e índice de comportamento do escoamento procedeuse a regressão múltipla para obtenção de uma equação polinomial completa. Eliminaram-se os coeficientes não significativos $(p>0,05)$, ajustado os dados a um melhor modelo, como mostram as equações 3 (índice de consistência) e 4 (índice de comportamento do escoamento).

$\mathrm{Y}_{3}=0,052-0,018 \cdot \mathrm{X}_{1}+0,034 \cdot \mathrm{X}_{2}($ Equação 3$)$

$\mathrm{Y}_{4}=1,149+0,106 \cdot \mathrm{X}_{1}-0,072 \cdot \mathrm{X}_{2}+0,055 \cdot \mathrm{X}_{2} \cdot \mathrm{X}_{3}$ (Equação 4)

A análise de variância dos modelos polinomiais para índice de consistência $(\mathrm{K})$ e índice de comportamento do escoamento (n) mostrou que os coeficientes de determinação para os modelos foram de 0,906 e 0,901 e o nível de significância de 0,059 e 0,065 , respectivamente.

$\mathrm{O}$ índice de consistência $(\mathrm{K})$ é dependente da variável $\mathrm{X}_{1}$ (soro de leite) e $\mathrm{X}_{2}$ (leite em pó), e o índice de comportamento do escoamento (n) é dependente da variável $X_{1}$ (soro de leite), $X_{2}$ (leite em pó) e da interação $X_{2} \cdot X_{3}$ (leite em pó e isolado proteico de soja).

As Figuras de 5 a 8 mostram as superfícies de resposta da relação entre as variáveis e os parâmetros reológicos. Quanto maior o teor de leite em pó e de soro de leite, maior o índice de consistência das bebidas lácteas e para o índice de comportamento do escoamento pode-se observar um aumento neste índice quanto maior o teor de soro de leite e de isolado proteico de soja e menor o teor de leite em pó. 


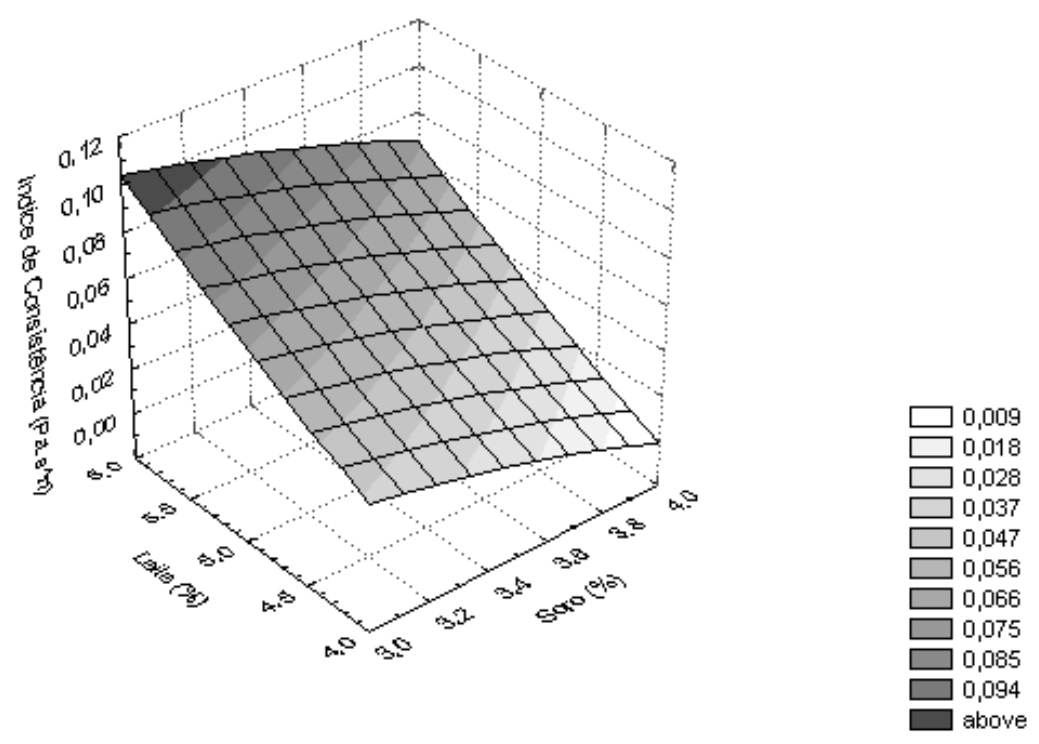

Figura 5. Efeito dos teores de soro de leite e leite em pó sobre índice de consistência (K) das bebidas lácteas, curvas descendentes.

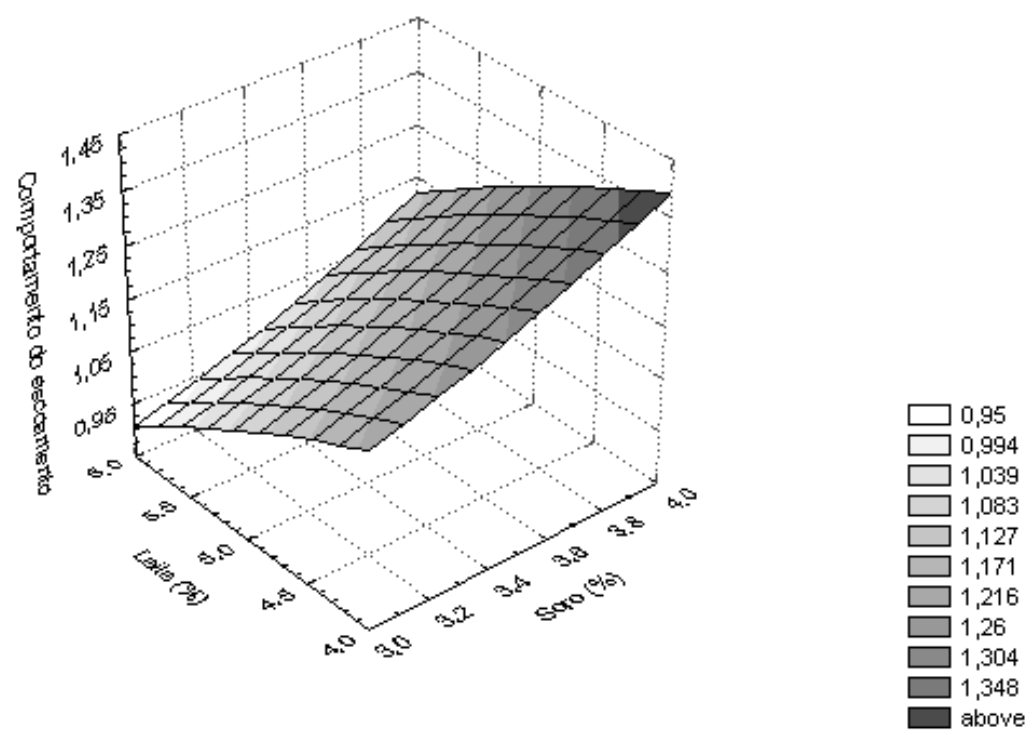

Figura 6. Efeito dos teores de soro de leite e leite em pó sobre o índice de comportamento do escoamento (n) nas curvas descendentes, fixando-se o teor de isolado proteico de soja em 1,5\%. 


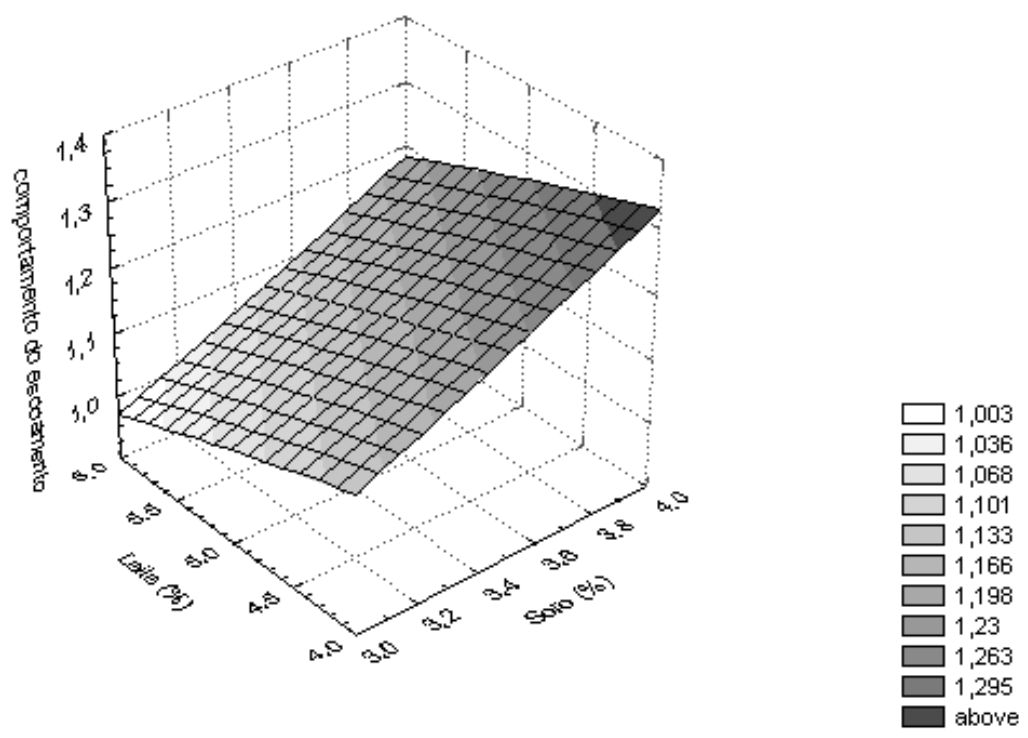

Figura 7. Efeito dos teores de soro de leite e leite em pó sobre o índice de comportamento do escoamento (n) nas curvas descendentes, fixando-se o teor de isolado proteico de soja em 2,0\%.
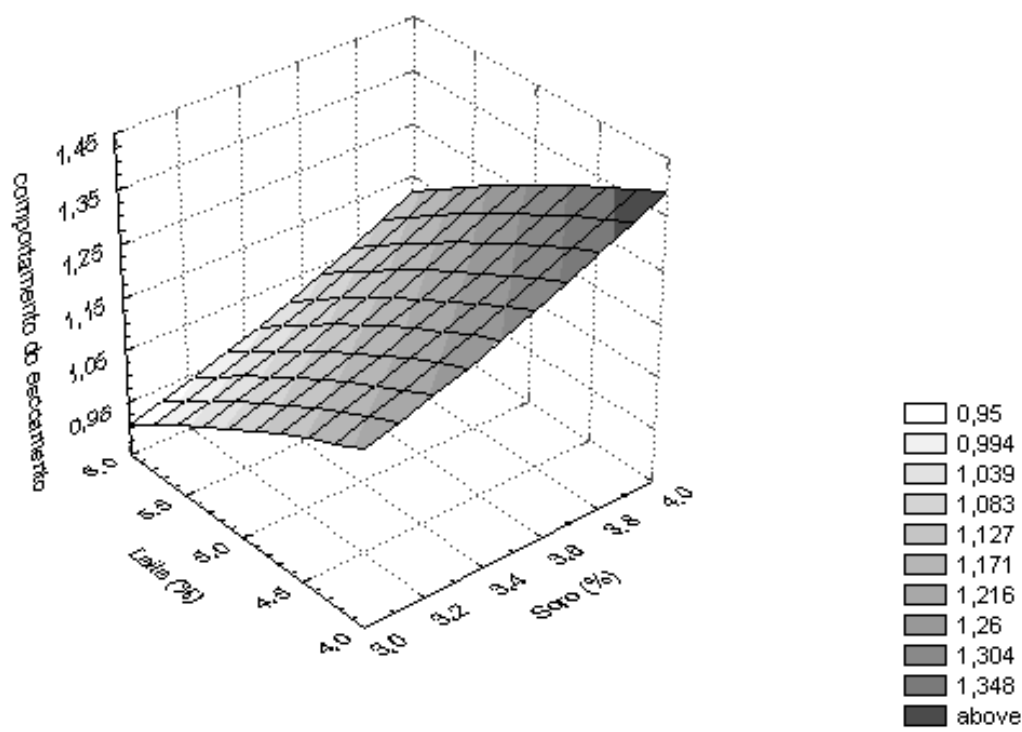

Figura 8. Efeito dos teores de soro de leite e leite em pó sobre o índice de comportamento do escoamento (n) nas curvas descendentes, fixando-se o teor de isolado proteico de soja em 2,5\%. 
O conhecimento das propriedades reológicas dos produtos lácteos é essencial para o projeto e manuseio de materiais e equipamentos de processos usados na indústria de laticínios. Certos produtos, quando submetidos à deformação, exibem tensão residual e amolecimento, aparentemente devido à quebra da estrutura. Entretanto a estrutura pode ser reconstituída com o tempo, quando o produto é levado à solidificação ou exibe um comportamento tixotrópico característicos de muitos produtos alimentícios (PRENTICE, 1992).

A bebida láctea do tratamento 3 , com elevada consistência e baixo índice de comportamento do escoamento (mais pseudoplástica) foi a que apresentou os maiores valores para os atributos sensoriais, demonstrando preferência dos consumidores por produtos mais encorpados. Além disso, as propriedades reológicas e sensoriais de produtos lácteos são influenciadas fortemente pelas características particulares de alguns ingredientes, como o índice gordura do leite, o tipo e a concentração do hidrocolóide, e das interações cruzadas entre estes componentes (TARREGA; COSTELL, 2006).

\section{Conclusões}

A bebida láctea preferida pelos provadores foi a elaborada com $3 \%$ de soro de leite, $6 \%$ de leite em pó desnatado e 1,5\% de isolado proteico de soja;

As variáveis leite em pó e isolado proteico de soja e a interação entre soro de leite e leite em pó têm um efeito positivo no atributo consistência sensorial. Quanto maior o teor destes ingredientes na formulação da bebida, mais os provadores gostaram da consistência das bebidas lácteas;

As bebidas apresentaram características de fluidos não Newtonianos, com presença de tixotropia, onde o índice de consistência $(\mathrm{K})$ ascendente e descendente depende das variáveis soro de leite e leite em pó, assim, quanto maior o teor de soro de leite e de leite em pó, maior foi a consistência;
O índice de comportamento do escoamento (n) ascendente dependente das variáveis soro de leite e leite em pó, enquanto o descendente depende das variáveis soro de leite, leite em pó e da interação entre o leite em pó e o isolado proteico de soja; quanto maior o teor de leite em pó e isolado proteico de soja, maior é o n.

\section{Agradecimentos}

Os autores agradecem à Fundação para o desenvolvimento da UNESP (FUNDUNESP) pelo suporte financeiro.

\section{Referências}

AWADHWAL, N. K.; SINGH, C. P. A rheological model for milk products. Journal of Food Science, Chicago, v. 50, n. 6, p. 1611-1614, 1985.

BANZATO, D. A.; KRONKA, S. D. Experimentação agricola. 3. ed. Jaboticabal: FUNESP, 1995.

BOBBIO, P. A.; BOBBIO, F. O. Química do processamento de alimentos. São Paulo: Varela, 1992.

BOX, G. E. P.; HUNTER, W. G.; HUNTER, J. S. Statistics for experimenters. New York: Wiley, 1978. p. 510-539.

BRANDÃO, S. C. C. Novas gerações de produtos lácteos funcionais. Revista Indústria de Laticínios, São Paulo, v. 6, n. 37, p. 64-66, 2002.

BRASIL. Ministério da Saúde. Secretaria de Vigilância Sanitária. Resolução no. 19, de 30 de abril 1999. Aprova o Regulamento Técnico de procedimentos para registro de alimento com alegação de propriedades funcionais e ou de saúde em sua rotulagem. Diário Oficial da União, Brasília, abr. 1999.

BUNGE ALIMENTOS. Proteína isolada de soja. Disponível em: $<$ http://www.bungealimentos.com.br $>$. Acesso em: 1 ago. 2003.

CAMPOS, S. D. S. Reologia e textura de alimentos. Campinas: ITAL, 1989. $84 \mathrm{p}$.

CARVALHO, F. V. Determinação de algumas características reológicas do leite adicionado de goma xantana e/ou glucomannan. 1990. Dissertação (Mestrado) - Escola Politécnica da Universidade de São Paulo, São Paulo, 1990. 
CICHOSKI, A. J.; CUNICO, C.; DI LUCCIO, M.; ZITKOSKI, J. L.; CARVALHO, R. T. Efeito da adição de probióticos sobre as características de queijo prato com reduzido teor de gordura fabricado com fibras e lactato de potássio. Ciências e Tecnologia de Alimentos, Porto Alegre, v. 2, n. 1, p. 35-38, 2008.

DRAKE, M. A.; CHEN, X. Q.; TAMARAPU, S.; LEENANON, B. Soy protein fortification affects sensory, chemical, and microbiological properties of dairy yogurts. Journal of Food Science, Chicago, v. 65, n. 7, p. 1244-1247, 2000.

ESTEVES, E. A.; MONTEIRO, J. B. R. Efeitos benéficos das isoflavonas de soja em doenças crônicas. Revista Nutrição, Campinas, v. 14, n. 1, p. 43-52, 2001.

FIORAVANTE, P. Combinação de ingredientes em iogurtes. Revista Flavors Magazine, Rio de Janeiro, n. 1, p. 48-49, 2001.

FOX, P. F.; MCSWEENEY, P. L. H. Dairy chemistry and biochemistry. London: Blackie. 1998.

GUEDES NETO, L. G.; FONSECA, L. M.; SOUZA, M. R. Defeitos tecnológicos de leites fermentados. Revista Leite e Derivados, São Paulo, v. 2, n. 74, p. 29-35, 2003.

HAQUE, A.; RICHARDSON, R. K.; MORRIS, E. R. Effect of fermentation temperature on the rheology of set and stirred yogurt. Food Hydrocolloids, Oxford, v. 15, n. 4, p. 593-602, 2001.

HOLDSWORTH, S. D. Rheological models used for the prediction of the flow properties of food products: a literature review. Transaction of Institute of Chemical Engineering, London, v. 71, part C, p. 139-179, 1993.

MADUREIRA, F. C. P. Desenvolvimento de uma bebida láctea funcional. 2004. Dissertação (Mestrado em Ciências e Tecnologia de Alimentos) - Instituto de Biociências, Letras e Ciências Exatas da Universidade Estadual "Júlio de Mesquita Filho", São José do Rio Preto, 2004.

MONTGOMERY, D. C. Design and analysis of experiments. New York: John Wiley, 2001.

MORAES, F. P.; COLLA, L. M. Alimentos Funcionais e Nutracêuticos: Definições, Legislação e Benefícios à Saúde. Revista Eletrônica de Farmácia, Goiânia, v. 3, n. 2, p. 109-122, 2006.

MORAES, M. A. C. Métodos para avaliação sensorial dos alimentos. Campinas: EDUNICAMP, 1983.

PENNA, A. L. B. Hidrocolóides: usos em alimentos. Food Ingredients, São Paulo, v. 1, n. 17, p. 58-64, 2000.
PENNA, A. L. B.; OLIVEIRA, M. N. Reologia de bebidas lácteas comerciais. In: CONGRESSO BRASILEIRO DE CIÊNCIA E TECNOLOGIA DE ALIMENTOS, 16., 1998, Rio de Janeiro. Anais... Rio de Janeiro: SBCTA, 1998.3 v, p. $1600-1603$.

PENNA, A. L. B.; SIVIERI, K.; OLIVEIRA, M. N. Relations between quality and rheological properties of lactic beverages. Journal of Food Engineering, Essex, v. 49 , n. 1, p. 7-13, 2001.

PINHEIRO, M. V. S. Caracterização de iogurtes fabricados com edulcorantes, fermentados por cultura láctica probiótica. 2003. Dissertação (Mestrado em Ciências e Tecnologia de Alimentos) - Instituto de Biociências, Letras e Ciências Exatas da Universidade Estadual "Júlio de Mesquita Filho", São José do Rio Preto, 2003.

PRENTICE, J. H. Dairy rheology: a concise guide. New York: VCH, 1992. 165 p.

PRUDÊNCIO, E.; FALCÃO, L. D.; BODIGNON LUIZ, M. T.; HAMAD, A. J. S.; BENET, H. D. Elaboração de uma bebida a partir de extrato de soja (Glycine Max) adicionada de soro de queijo e antioxidantes. In.: CONGRESSO BRASILEIRO DE CIÊNCIA E TECNOLOGIA DE ALIMENTOS, 18., 2002, Porto Alegre. Anais... Porto Alegre: SBCTA, 2002. p. 30553058 .

PUPIN, A. M. Legislação dos produtos lácteos funcionais. In: PORTUGAL, J. A. B.; et. al. O agronegócio do leite e os alimentos lácteos funcionais. Juiz de Fora: EPAMIG/ ILCT, 2001. 204 p.

RENKEMA, J. M. S. Relation betweens rheological properties and network struture of soy protein gels. Food Hidrocolloids, Oxford, v. 18, n. 1, p. 39-47, 2004.

SANTOS, J. A. Tendências dos ingredientes que dão um diferencial ao produto iogurte. Leite \& Derivados, São Paulo, v. 1, n. 63, p. 48-53, 2002.

SOCIEDADE BRASILEIRA DE ALIMENTOS FUNCIONAIS - SBAF. Alimentos funcionais crescem 50\%. Disponível em: $<\mathrm{http}: / /$ www.sbaf.org.br $>$. Acesso em: 22 de jan. 2008.

STEFFE, J. F. Rheological methods in food process engineering. East Lansing: Fremann Press, 1996.

TARREGA, A.; COSTELL, E. Effect of composition on the rheological behaviour and sensory properties of semisolid dairy dessert. Food Hydrocolloids, Oxford, v. 20, n. 6, p. 914-922, 2006. 
TORTELLI, S. Desenvolvimento de bebidas lácteas fermentadas utilizando como substrato extrato hidrossolúvel de soja e soro de leite. 2002. Monografia (Trabalho de Conclusão de Curso) - Universidade Regional Integrada do Alto Uruguai e das Missões, Erechim, 2002.

VÉLEZ-RUIZ, J. F.; BARBOSA-CÁNOVAS, G. V. Rheological properties of concentrated milk as a function of concentration, temperature and storage time. Journal of Food Engineering, Essex, v. 35, n. 2, p. 177-190, 1998.

VITALI, A. A. Comportamento reológico de suco de laranja concentrado congelado à baixas temperaturas. 1983. Tese (Doutorado em Engenharia) - Escola Politécnica da Universidade de São Paulo, São Paulo, 1983. 
